MaPan : Jurnal Matematika dan Pembelajaran

p-ISSN: 2354-6883 ; e-ISSN: 2581-172X

Volume 5, Nomor 1, Juni 2017

\title{
PENGEMBANGAN BAHAN AJAR MATEMATIKA KELAS VII SMP BERDASARKAN MODEL PEMBELAJARAN KOLB-KNISLEY BERBANTUAN GEOGEBRA SEBAGAI UPAYA MENINGKATKAN HIGHER-ORDER THINKING SKILL DAN APRESIASI SISWA TERHADAP MATEMATIKA
}

\author{
Fitriani Nur \\ Fakultas Tarbiyah dan Keguruan UIN Alauddin Makassar \\ Kampus II: Jalan H. M. Yasin Limpo Nomor 36 Samata-Gowa \\ E-mail: fitrianinur818@gmail.com
}

\begin{abstract}
Abstrak
Penelitian ini bertujuan untuk menghasilkan bahan ajar matematika kelas VIII SMP berdasarkan model pembelajaran Kolb-Knisley berbantuan geogebra untuk meningkatkan higher-order thinking skill dan apresiasi siswa kelas VIII SMP dengan menggunakan bahan ajar matematika berdasarkan model pembelajaran Kolb-Knisley. Jenis penelitian ini adalah penelitian pengembangan dengan mengadopsi model pengembangan ADDIE. Hasil penelitian dan pengembangan menunjukkan bahwa bahan ajar Kolb-Knisley yang dihasilkan dapat dijadikan sebagai salah satu media pembelajaran, berdasarkan penilaian dari validator diketahui bahwa secara keseluruhan bahwa bahan ajar ini tergolong dalam kategori sangat baik dengan persentase sebesar 88,33\%, berdasarkan uji coba kelompok kecil higher order thinking skill siswa setelah menggunakan bahan ajar Kolb-Knisley meningkat dengan persentase ketuntasan sebesar 100\%, beradasarkan uji coba kelompok kecil dapat diketahui bahwa rata-rata apresiasi siswa terhadap matematika sebelum menggunakan produk yang dikembangkan sebesar 73,66 dan berada pada kategori sedang. Sedangkan apresiasi siswa terhadap matematika setelah menggunakan produk yang dikembangkan sebesar 103,60 dan berada pada kategori sangat tinggi. Berdasarkan hasil angket respon siswa terhadap bahan ajar Kolb-Knisley diperoleh persentase sebesar 95\%. Secara keseluruhan, bahan ajar Kolb-Knisley yang telah dikembangkan oleh pengembang diketahui sangat baik.
\end{abstract}

Kata Kunci: Model Pembelajaran Kolb-Knisley, Geogebra, Higher-Order Thinking Skill, Apresiasi Siswa

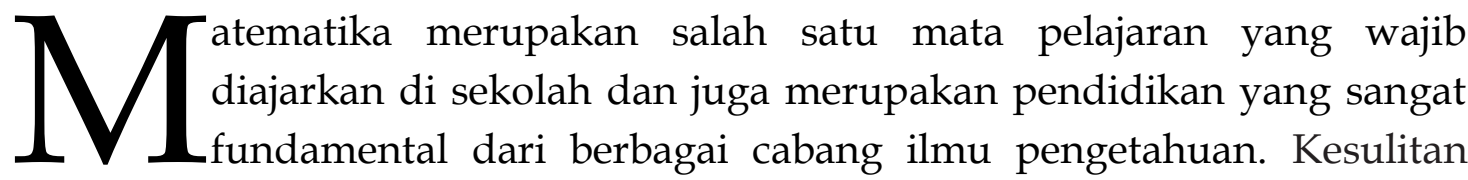


belajar yang dihadapi siswa dalam mempelajari matematika sudah tentu merupakan penyebab rendahnya hasil belajar siswa dan salah satu hasil belajar yang rendah tersebut adalah higher order thinking skill.

Berdasarkan laporan hasil ujian nasional BNSP tahun 2016 terlihat bahwa kemampuan siswa SMP Islam Al-Azhar menjawab soal-soal geometri khususnya materi lingkaran terlihat masih rendah, dapat diketahui dari laporan tersebut persentase penguasaan materi lingkaran pada tingkat sekolah sebesar 70,00, pada tingkat kota/kabupaten sebesar 70,55, propinsi sebesar 63,74, sedangkan pada tingkat nasional sebesar 51,30. Berdasarkan beberapa faktor yang telah dijelaskan di atas, tampak bahwa model pembelajaran dan materi pelajaran yang menjadi salah satu penyebab rendahnya higher order thinking skill siswa.

Buku yang dipakai oleh guru sebagai penunjang dalam proses pembelajaran merupakan bagian dari bahan ajar yang dikelompokkan dalam bahan ajar cetak. Bahan ajar yang digunakan dalam proses pembelajaran hendaknya disusun dengan menggunakan model yang sesuai dengan karakteristik dan mata pelajaran melalui aktivitas eksplorasi, elaborasi, dan konfirmasi. Dalam melaksanakan aktivitas tersebut dapat dilakukan secara interaktif, inspiratif, menyenangkan, dan menantang, sehingga memotivasi siswa untuk berpartisipasi aktif dalam proses pembelajaran (Departemen Pendidikan Nasional, 2007).

Berdasarkan pendapat di atas, bahan ajar yang memiliki sifat-sifat tersebut sesuai dengan bahan ajar yang dikembangkan dengan model pembelajaran matematika Kolb-Knisley. Selain itu, salah satu cara yang dapat mendukung optimalnya pembelajaran ini adalah dengan menggunakan media pembelajaran. Menurut Hamalik dalam Azhar Arsyad (2011: 15) penggunaan media pembelajaran akan membantu keefektifan pembelajaran dalam menyampaikan isi materi pada saat itu. Salah satu media pembelajaran yang saat ini sangat membantu proses pembelajaran di kelas adalah media pembelajaran berbasis komputer. Salah satu media pembelajaran yang dirasa cocok digunakan guru dalam mengembangkan proses pembelajarannya adalah Software GeoGebra

Berdasarkan latar belakang tersebut di atas maka penulis akan melaksanakan penelitian dengan judul Pengembangan Bahan Ajar Matematika Kelas VII SMP Berdasarkan Model Pembelajaran Kolb-Knisley Berbantuan Geogebra Sebagai Upaya Meningkatkan Higher-Order Thinking Skill dan Apresiasi Siswa Terhadap Matematika. Selain itu, penelitian ini pertujuan 
pula untuk menghasilkan bahan ajar matematika kelas VIII SMP berdasarkan model pembelajaran Kolb-Knisley berbantuan geogebra untuk meningkatkan higher-order thinking skill dan apresiasi siswa kelas VIII SMP dengan menggunakan bahan ajar matematika berdasarkan model pembelajaran KolbKnisley

\section{PEMBELAJARAN MATEMATIKA SMP}

Menurut James \& James (Suherman, 2003: 7) mengatakan bahwa matematika adalah ilmu tentang logika mengenai bentuk, susunan, besaran, konsep-konsep yang berhubungan satu dengan yang lainnya dengan jumlah yang banyak yang terbagi ke dalam tiga bidang, yaitu aljabar, analisis, dan geometri. Penguasaan matematika yang diperlukan secara umum termuat dalam tujuan pembelajaran matematika Permendiknas No. 22 Tahun 2006, mata pelajaran matematika bertujuan agar peserta didik memiliki kemampuan berikut:

a. Memahami konsep matematika, menjelaskan keterkait anantar konsep dan mengaplikasikan konsep atau algoritma.

b. Menggunakan penalaran pada pola dan sifat, melakukan manipulasi matematika dalam membuat generalisasi, menyusun bukti, atau menjelaskan gagasan dan pernyataan matematika.

c. Memecahkan masalah yang meliputi kemampuan memahami masalah, merancang model matematika, menyelesaikan model dan menafsirkan solusi yang diperoleh.

d. Mengomunikasikan gagasan dengan simbol, tabel, diagram, atau media lain untuk memperjelas keadaan atau masalah.

e. Memiliki sikap menghargai kegunaan matematika dalam kehidupan, yaitu memiliki rasa ingin tahu, perhatian, dan minat dalam mempelajari matematika, serta sikap ulet dan percaya diri dalam pemecahan masalah.

\section{BAHAN AJAR BERBANTUAN SOFWARE GEOGEBRA}

Menurut National Centre for Competency Based Training (2007) bahan ajar adalah segala bentuk bahan (terulis maupun tidak tertulis) yang digunakan untuk membantu guru atau instruktur dalam melaksanakan proses pembelajaran. Sedangkan menurut Paul S. Ache dalam Depdiknas (2008: 6) mengemukakan tentang material yaitu buku yang dapat digunakan sebagai bahan rujukan, atau dapat digunakan sebagai bahan tertulis yang berbobot. 
GeoGebra adalah software matematika yang mudah digunakan, baik padamateri geometri, aljabar, dan kalkulus. Hohenwarter \& Fuchs (2004: 3) menjelaskan GeoGebra sangat bermanfaat sebagai media pembelajaran matematika dengan beragam aktivitas sebagai berikut:

a. Sebagai media demonstrasi dan visualisasi. Dalam hal ini, dalampembelajaran yang bersifat tradisional, guru memanfaatkan GeoGebra untuk mendemonstrasikan dan memvisualisasikan konsep konsep matematikatertentu.

b. Sebagai alat bantu konstruksi. Dalam hal ini GeoGebra digunakan untukmemvisualisasikan konstruksi konsep matematika tertentu, misalnyamengkonstruksi lingkaran dalam maupun lingkaran luar segitiga, atau garissinggung.

c. Sebagai alat bantu proses penemuan. GeoGebra digunakan untuk alat bantubagi siswa untuk menemukan suatu konsep matematis, misalnya tempat kedudukan titik-titik atau karakteristik parabola.

\section{MODEL PEMBELAJARAN MATEMATIKA KOLB- KNISLEY}

Menurut Nasution model Kolb didasarkan atas psikologi Jung yang berlangsung melalui 4 fase atau tahap yakni.

a. Individu memperoleh pengalaman langsung yang konkrit

b. Kemudian ia mengembangkan observasinya dan memikirkan atau merefleksikannya,

c. Dari itu dibentuknya generalisasi dan abstraksi

d. Implikasi yang diambilnya dari konsep-konsep itu dijadikannya sebagai pegangannya dalam menghadapi pengalaman-pengalaman baru.

Jadi, model pembelajaran matematika Kolb-Knisley adalah model pembelajaran yang terdiri dari empat langkah yaitu kongkret reflektif, kongkret aktif, abstrak reflektif, dan abstrak aktif.

\section{HASIL BELAJAR}

\section{Higher Order Thinking Skill}

Menurut Brookhart (2010: 3) pengertian dari higher order thinking skill mencakup kategori berikut (1) those that define higher-order thinking in terms of transfer, (2) those that define it in terms of critical thinking, and (3) those that define it in terms of problem solving. Artinya higher order thinking bisa berarti mentransfer, berpikir kritis, dan pemecahan masalah. Menurut Krulik dan Rudnick (1995: 2), bahwa penalaran mencakup berpikir dasar (basic thinking), berpikir kritis 
(critical thinking), dan berpikir kreatif (creative thinking). Kemampuan berpikir inilah yang termasuk dalam kemampuan berpikir tingkat tinggi.

\section{Apresiasi}

Menurut Barret (2007: 650) "appreciation results from an act of judgement, and a responsive judgement (positive or negative) is dependent on an interpretation". Artinya apresiasi merupakan hasil dari tindakan penilaian atau penghakiman berupa penilaian baik atau buruk.

Berdasarkan pendapat di atas, apresiasi yang dimaksud dalam penelitian ini adalah suatu aktivitas berupa penilaian, penghargaan, penghakiman baik atau bruk, kesadaran, kebermanfaatan, dan partisipasi.

\section{METODE PENELITIAN}

Penelitian ini bertujuan untuk menghasilkan produk berupa bahan ajar matematika menggunakan model pembelajaran Kolb-Knisley berbantuan software geogebra. Menurut Sukmadinata (2009: 164), penelitian pengembangan adalah suatu proses atau langkah-langkah untuk mengembangkan suatu produk baru atau menyempurnakan produk yang telah ada, yang dapat dipertanggungjawabkan.

Model pengembangan yang akan digunakan dalam penelitian ini mengadopsi model pengembangan ADDIE yang terdiri dari lima langkah atau tahap yaitu Analysis (analisa), Design (perancangan/desain), Development (pengembangan), Implementation (implementasi) and Evaluation (evaluasi). Model pengembangan ini dikembangkan oleh Dick and Carry (1996).

Secara garis besar tahap-tahap pengembangan yang ada pada penelitian ini sesuai dengan tahap model pengembangan ADDIE yaitu tahap analisis, tahap desain, pengembangan (development), implementasi.

Adapun instrumen yang digunakan dalam penelitian ini terdiri dari Lembar validasi oleh ahli materi dan ahli pendidikan,Lembar angket respon siswa,Lembar angket apresiasi siswa terhadap matematika, Lembar soal pretes dan postes HOTS.

Pengolahan data angket ahli materi, ahli pendidikan, dan respon siswa diolah bedasarkan aturan pembobotan yang telah ditetapkan seperti pada tabel berikut ini. 
Tabel 1. Penetapan Skor Untuk Hasil Penilaian Ahli Materi dan Ahli Pendidikan

\begin{tabular}{cc}
\hline Jawaban & Skor Pernyataan Positif \\
\hline Sangat baik & 5 \\
Baik & 4 \\
Cukup & 3 \\
Kurang baik & 2 \\
Sangat kurang baik & 1 \\
\hline
\end{tabular}

Data tentang apresiasi siswa terhadap matematika diperoleh dengan menggunakan instrumen non-tes yang berbentuk checklist dengan skala Likert seperti pada tabel 2 di bawah ini.

Tabel 2. Penetapan Skor Untuk Hasil Penilaian Apresiasi Siswa

\begin{tabular}{cccccc}
\hline Pernyataan & $\begin{array}{c}\text { Sangat } \\
\text { Setuju }\end{array}$ & Setuju & $\begin{array}{c}\text { Netral/ } \\
\text { Ragu }\end{array}$ & $\begin{array}{c}\text { Tidak } \\
\text { Setuju }\end{array}$ & $\begin{array}{c}\text { Sangat Tidak } \\
\text { Setuju }\end{array}$ \\
\hline $\begin{array}{c}\text { Pernyataan } \\
\text { Positif }\end{array}$ & 5 & 4 & 3 & 2 & 1 \\
$\begin{array}{c}\text { Pernyataan } \\
\text { Negatif }\end{array}$ & 1 & 2 & 3 & 4 & 5 \\
\hline
\end{tabular}

Angket ini terdiri dari 25 butir pernyataan, sehingga skor minimum idealnya adalah, sedangkan skor maksimum idealnya adalah 125 . Sehingga skor ideal $(\mathrm{Si})$ dan rata-rata ideal $(\mathrm{Mi})$ dapat ditentukan sebagai berikut: $\mathrm{Mi}=(125+25) / 2=75$ dan $\mathrm{Si}=(125+25) / 6=25$. Setelah memperoleh data mengenai apresiasi siswa terhadap matematika dikategorikan berdasarkan tabel di bawah ini.

Tabel 3. Apresiasi Siswa Terhadap Matematika

\begin{tabular}{ccc}
\hline Interval & $\begin{array}{c}\text { Interval Skor } \\
\text { KD }\end{array}$ & Kriteria \\
\hline $\mathrm{Mi}+1.5 \mathrm{Si}<\mathrm{X} \leq \mathrm{Mi}+3 \mathrm{Si}$ & $100<\mathrm{X} \leq 125$ & Sangat Tinggi \\
$\mathrm{Mi}+0.5 \mathrm{Si}<\mathrm{X} \leq \mathrm{Mi}+1.5 \mathrm{Si} i$ & $83,3<\mathrm{X} \leq 100$ & Tinggi \\
$\mathrm{Mi}-0.5 \mathrm{Si}<\mathrm{X} \leq \mathrm{Mi}+0.5 \mathrm{Si} i$ & $66,7<\mathrm{X} \leq 83,3$ & Sedang \\
$\mathrm{Mi}-1.5 \mathrm{Si}<\mathrm{X} \leq \mathrm{Mi}-0.5 \mathrm{Si} i$ & $50<\mathrm{X} \leq 66,7$ & Rendah \\
$\mathrm{Mi}-3 \mathrm{Si} \leq \mathrm{X} \leq \mathrm{Mi}-1.5 \mathrm{Si}$ & $25 \leq \mathrm{X} \leq 50$ & Sangat Rendah \\
\hline
\end{tabular}




\section{HASIL PENELITIAN DAN PEMBAHASAN \\ Deskripsi Pengembangan Produk Awal}

Produk awal yang telah dibuat dalam pengembangan ini terdiri dari tiga tahapan pengembangan yaitu:

a. Perencanaan

Pada tahapan ini tim peneliti menentukan tujuan pembelajaran termasuk SK dan KD, menentukan software apa yang akan digunakan dan sesuai dengan materi yang akan dibahas, menentukan model pembelajaran yang cocok dengan materi yang akan dibahas.

b. Desain

Pada tahap ini, langkah pertama yang dilakukan peneliti adalah merancang bahan ajar yang akan dibuat dengan maksud memperoleh prototype. Langkah kedua adalah menyusun tes hasil belajar berdasarkan tujuan yang akan dicapai dalam pembelajaran lingkaran. Langkah ketiga adalah memilih software geogebra. Langkah keempat adalah memilih format apa yang akan digunakan untuk mendesain isi, model pembelajaran serta sumber belajar, dan menggunakan model pembelajaran matematika KolbKnisley.

c. Pengembangan

Tahap ini merupakan tahap akhir dalam pembuatan produk awal dengan menghasilkan satu draft perangkat pembelajaran berdasarkan desain yang telah ditentukan. Produk awal yang telah dibuat kemudian divalidasi oleh para ahli yang telah dipilih. Berikut ini gambaran Bahan Ajar KolbKnisley

1) Materi :Operasi Hitung Bentuk Aljabar

2) Ketebalan : $₫ 42$ halaman

3) Jenis huruf : Snap ITC, Times New Roman, Monotype Corsiva, Jokerman

4) Format : Portabel Document Format (PDF)

Berdasarkan produk awal yang telah direvisi langkah selanjutnya adalah melaksanakan uji coba. Tahap uji coba ini terdiri dari 2 tahap yaitu mengkonsultasikan bahan ajar yang telah dibuat ke validator kemudian melakukan uji coba terbatas. 


\section{Hasil Uji Coba Produk}

a. Uji Ahli

Instrumen yang digunakan dalam penelitian ini adalah divalidasi oleh dua orang ahli yaitu Nursalam selaku ahli pendidikan dan Muhammad Nasir selaku ahli materi. Adapun hasil dari kedua validator tersebut dapat dilihat pada tabel berikut ini.

Tabel 4. Hasil Uji Angket Menurut Sudut Pandang Ahli Pendidikan

\begin{tabular}{ccccc}
\hline No. & Komponen & Skor & Persentase(\%) & Kategori \\
\hline 1 & Kelayakan Isi & 3,62 & 75 & Baik \\
2 & Kebahasaan & 4,6 & 92 & Sangat Baik \\
3 & Penyajian & 4,4 & 95 & Baik \\
& Total & 4,33 & 87 & Baik \\
\hline
\end{tabular}

Beberapa saran yang telah diperoleh dari ahli pendidikan terdiri dari tiga poin yaitu: 1) belum ada rumusan standar kompetensi dan indikator pembelajaran, 2) semua gambar yang didownload harus ada sumbernya dan yang terakhir adalah, 3) semua gambar lingkaran diperbaiki agar lebih jelas. Setelah mendapatkan saran dari ahli pendidikan, bahan ajar kemudian direvisi berdasarkan saran tersebut.

Selanjutnya data hasil penilaian dari ahli materi. Data ini merupakan data yang diperoleh dari ahli materi atas tanggapan atau penilaian serta saran-saran perbaikan yang digunakan untuk memperbaiki kualitas produk yang dikembangkan. Berikut ini adalah tabel dari hasil penilaian ahli materi.

Tabel 5. Hasil Uji Angket Menurut Sudut Pandang Ahli Materi

\begin{tabular}{|c|c|c|c|c|}
\hline No. & Komponen & Skor & Persentase (\%) & Kategori \\
\hline 1 & Kelayakan Isi & 4,4 & 89 & Sangat Baik \\
\hline 2 & Kebahasaan & 4,5 & 90 & Sangat Baik \\
\hline 3 & Penyajian & 4,5 & 90 & Sangat Baik \\
\hline & Total & 4,5 & 89,66 & Sangat Baik \\
\hline
\end{tabular}

b. Data Uji Coba Terbatas

Data Uji coba kelompok kecil ini terdiri dari 6 orang siswa dari SMP 4 Al-Azhar yang dipilih secara acak berdasarkan kemampuan yang dimilikinya yaitu kemampuan atas, menengah, dan bawah. Data higher order thinking skill 
dan apresiasi siswa terhadap matematika yang dimaksud dapat dilihat pada tabel berikut ini.

Tabel 6. Hasil Nilai HOTS Pretest dan Posttest Uji Coba Terbatas

\begin{tabular}{ccccc}
\hline \multirow{2}{*}{ No. Urut Siswa } & \multicolumn{2}{c}{ Nilai Pretest } & \multicolumn{2}{c}{ Nilai Posttest } \\
\cline { 2 - 5 } & Nilai & Ketuntasan & Nilai & Ketuntasan \\
\hline 1 & 45 & Tidak Tuntas & 75 & Tuntas \\
2 & 34 & Tidak Tuntas & 80 & Tuntas \\
3 & 40 & Tidak Tuntas & 77 & Tuntas \\
4 & 55 & Tidak Tuntas & 77 & Tuntas \\
5 & 44 & Tidak Tuntas & 78 & Tuntas \\
6 & 58 & Tidak Tuntas & 80 & Tuntas \\
\hline Rata-rata & 46 & & 77,83 & \\
\hline Ketuntasan $(\%)$ & \multicolumn{2}{c}{ Sangat Tinggi } \\
\hline Kriteria & \multicolumn{2}{c}{ Sangat Rendah } & \multicolumn{2}{c}{} \\
Ketuntasan & \multicolumn{2}{c}{}
\end{tabular}

Berdasarkan nilai rata-rata siswa pada pretestyang memperoleh nilai sebesar 46,00 dengan KKM 60 dapat diketahui bahwa semua siswa mendapatkan nilai yang tidak tuntas. Ini juga berarti bahwa perolehan nilai siswa dikatakan sangat rendah. Di lain pihak, nilai rata-rata siswa pada posttest diperoleh sebesar 77,83 dan seluruh siswa mendapatkan nilai yang tuntas sehingga ketuntasan siswa pada posttest tersebut dikatakan sangat tinggi.

Tabel 7. Hasil Nilai ApresiasiAwal dan Akhir Uji Coba Terbatas

\begin{tabular}{|c|c|c|c|c|}
\hline \multirow{2}{*}{$\begin{array}{l}\text { No. Urut } \\
\text { Siswa }\end{array}$} & \multicolumn{2}{|c|}{ Apresiasi Awal } & \multicolumn{2}{|c|}{ Apresiasi Akhir } \\
\hline & Total Nilai & Kriteria & Total Nilai & Kriteria \\
\hline \multirow[t]{2}{*}{1} & 86 & Tinggi & 103 & Sangat \\
\hline & & & & Tinggi \\
\hline \multirow[t]{2}{*}{2} & 78 & Sedang & 103 & Sangat \\
\hline & & & & Tinggi \\
\hline \multirow[t]{2}{*}{3} & 80 & Sedang & 114 & Sangat \\
\hline & & & & Tinggi \\
\hline \multirow[t]{2}{*}{4} & 64 & Rendah & 103 & Sangat \\
\hline & & & & Tinggi \\
\hline 5 & 63 & Rendah & 100 & Tinggi \\
\hline
\end{tabular}




\begin{tabular}{ccccc}
\hline 6 & 71 & Sedang & 98 & Tinggi \\
\hline Rata-rata & 73,66 & Sedang & 103,60 & $\begin{array}{c}\text { Sangat } \\
\text { Tinggi }\end{array}$ \\
\hline
\end{tabular}

Berdasarkan uji coba di atas dapat pula diketahui bahwa produk yang dikembangkan telah memenuhi kriteria yang diharapkan, yaitu ketuntasan belajar siswa dan apresiasi siswa terhadap matematika pada tes akhir melebihi yang diharapkan. Harapan ketuntasan belajar dan apresiasi siswa terhadap matematika dalam penelitian ini berada pada kategori "Tinggi".

Tabel 12. Hasil Nilai Respon Siswa Terhadap Bahan Ajar Kolb-Knisley

\begin{tabular}{|c|c|c|c|c|}
\hline \multirow{2}{*}{ No. } & \multirow{2}{*}{ Pernyataan } & \multicolumn{2}{|c|}{ Jawaban } & \multirow{2}{*}{$\begin{array}{c}\text { Persentase } \\
(\%)\end{array}$} \\
\hline & & SS & $S$ & \\
\hline 1 & $\begin{array}{l}\text { Saya senang belajar matematikamenggunakan } \\
\text { bahan ajar Kolb-Knisleykarena penjelasan } \\
\text { materinya mudah dipahami }\end{array}$ & 5 & 1 & 96 \\
\hline 2 & $\begin{array}{l}\text { Saya menjadi lebih bersemangat dan } \\
\text { termotivasi dalam belajar matematika setelah } \\
\text { menggunakan bahan ajar Kolb-Knisley }\end{array}$ & 2 & 4 & 86 \\
\hline 3 & $\begin{array}{l}\text { Bahan ajar Kolb-Knisley memuat kegiatan } \\
\text { belajar yang menarik yang menimbulkan rasa } \\
\text { keingintahuan saya }\end{array}$ & 5 & 1 & 96 \\
\hline 4 & $\begin{array}{l}\text { Aktivitas pada bahan ajar Kolb-Knisley } \\
\text { menuntun saya untuk bekerja sama dengan } \\
\text { teman atau berinteraksi dengan lingkungan }\end{array}$ & 6 & 0 & 100 \\
\hline 5 & $\begin{array}{l}\text { Penggunaan bahasa dalam bahan ajar ini } \\
\text { mudah saya pahami }\end{array}$ & 3 & 3 & 90 \\
\hline 6 & $\begin{array}{l}\text { Ilustrasi dan kasus yang terdapat pada bahan } \\
\text { ajar Kolb-Knisley berkaitan dengan kehidupan } \\
\text { sehari-hari }\end{array}$ & 6 & 0 & 100 \\
\hline 7 & $\begin{array}{l}\text { Saya senang mempelajari bahan ajar Kolb- } \\
\text { Knisley karena tampilannya menarik }\end{array}$ & 5 & 1 & 96 \\
\hline 8 & $\begin{array}{l}\text { Soal-soal yang ada pada bahan ajar mudah } \\
\text { saya pahami }\end{array}$ & 3 & 3 & 90 \\
\hline 9 & $\begin{array}{l}\text { Saya dapat memahami setiap fase yang ada } \\
\text { pada bahan ajar ini }\end{array}$ & 6 & 0 & 100 \\
\hline 10 & Pembelajaran matematika menjadi lebih & 6 & 0 & 100 \\
\hline
\end{tabular}


menyenangkan dengan menggunakan bahan

ajar ini

Total

95,4

\section{Produk Akhir Bahan Ajar Realistik}

Setelah dilakukan beberapa tahapan penelitian maka dihasilkan satu produk akhir Bahan Ajar Kolb-Knisley. Produk akhir Bahan Ajar Kolb-Knisley ini terdiri dari 6 bagian yaitu pembuka, pengertian lingkaran, unsur-unsur lingkaran, keliling lingkaran, pendekatan luas lingkaran, serta sudut pusat dan sudut keliling. Produk akhir ini merupakan penyempurnaan dari produk desain awal yang telah dihasilkan setelah diuji cobakan. Produk akhir ini dihasilkan setelah dilakukan beberapa perbaikan dari segi penulisan materi, tujuan pembelajaran, gambar, tata letak, serta pengertian dari setiap konsep. Adapun gambaran produk akhir Bahan Ajar Kolb-Knisey yaitu:

1) Materi : Lingkaran Kelas VIII SMP

2) Media penyimpanan : CD-R dan Kertas 80 gr.

3) Ukuran : $17,5 \mathrm{~cm} \times 25 \mathrm{~cm}$

4) Ukuran file : 10,1 MB

5) Ketebalan : 42 halaman

6) Format : Portabel Document Format (PDF)

7) Jenis huruf : Snap ITC, Times New Roman, Monotype Corsiva, Jokerman

\section{Kajian Produk Akhir}

Berdasarkan uji kelompok kecil dan evaluasi dari dua uji ahli yang telah dilakukan dapat diketahui bahwa produk yang dikembangkan menunjukkan bahwa bahan ajar ini layak digunakan dalam kegiatan pembelajaran. Hal ini dapat dilihat dari hasil penilaian ahli media dan pendidikan serta respon siswa yang mendapatkan kriteria sagat baik. Penggunaan bahasa yang digunakan juga mudah dipahami. Serta dengan bantuan software geogebra siswa bisa melihat dengan jelas gambar lingkaran berdasarkan konsep yang dijelaskan. Bahan ajar Kolb-Knisley yang telah dikembangkan ini menggunakan empat tahapan sesuai dengan MPMK-K. Bahan ajar ini juga memfasilitasi HOTS dan apresiasi siswa terhadap matematika. 


\section{Tahapan MPMK-K}

\section{a) Fase Konkret Reflektif}

Tahapan ini berisi permasalahan mengenai materi yang berhubungan dengan konteks kehidupan sehari-hari yang juga diartikan sebagai konsep awal yang telah diketahui oleh siswa guna mengarahkan pola pikir siswa tentang pengenalan awal konsep lingkaran. Selain itu bagian ini juga dapat digunakan untuk merumuskan konsep baru berdasarkan contoh konkret yang telah diketahuinya.

b) Fase Konkret Aktif

Pada tahapan ini siswa mulai mencoba untuk mengukur, menggambar, menghitung, dan membandingkan untuk membedakan konsep baru dengan konsep lama yang telah diketahuinya.

c) Fase Abstrak Reflektif

Abstrak reflektif digunakan untuk menghubungkan konsep baru dengan konsep yang telah diketahui oleh siswa kemudian membuat suatu kesimpulan.

d) Fase Abstarak Aktif

Pada tahapan ini siswa akan menyelesaikan masalah berdasarkan konsep (kesimpulan) yang telah mereka bentuk.

\section{Fasilitasi HOTS dan Apresiasi}

Berdasarkan beberapa tahapan yang ada dalam bahan ajar Kolb-Knisley yaitu konkret reflektif, konkret aktif, abstrak reflektif, dan abstrak aktif dapat disimpulkan bahwa keempat tahapan ini ada kaitannya dengan proses pengembangan higher order thinking skill siswa.Selain itu dengan menghubungkan materi dengan kehidupan sehari-hari siswa, budaya, dan penggunaan teknologi berupa software geogebra dalam pembelajarannya telah memberikan penilaian yang baik terhadap matematika. Penilaian ini berupa kesadaran siswa tentang kebermanfaatan matematika dalam kehidupannya sehari-hari, dan kebermanfaatan teknologi dalam pembelajaran matematika karena bahan ajar ini disesuaikan dengan sesuatu yang tidak asing lagi bagi mereka.

Produk ini memiliki beberapa kelebihan dalam penggunaanya yaitu, bahan ajar ini bisa digunakan dengan atau tanpa bantuan oleh guru karena sajian materi dalam bahan ajar ini disajikan sesuai dengan hirarki matematika. Penggunaan bahasa yang sederhana telah memfasilitasi pemahaman siswa agar lebih mudah mengerti. Siswa yang kemampuannya rendah tidak akan 
merasa tertinggal lagi dalam pembelajarannya karena tahap-tahap demi tahap konsep mengenai lingkaran dijelaskan dengan rinci, siswa bisa menggunakan bahan ajar ini dimana saja dan kapan saja. Perpaduan warna yang baik dan menarik membuat siswa tidak bosan melihat bahan ajar ini. Selain memiliki kelebihan terdapat pula kelemahan yang ada pada bahan ajar ini diantaranya adalah proses pembuatannya memerlukan waktu yang cukup lama dan tidak semua siswa mampu menggunakan software geogebra.

\section{SIMPULAN}

Berdasarkan penelitian dan pengembangan yang telah dilakukan, dapat diambil simpulan bahwa bahan ajar Kolb-Knisley yang dihasilkan dapat dijadikan sebagai salah satu media pembelajaran yang efektif digunakan khususnya untuk pembelajaran pada pokok bahasan Lingkaran. Bahan ajar inidiharapkan dapat membantu guru dalam proses pembelajarannya dan diharapkan dapat membuat pembelajaran siswa lebih menarik berdasarkan tuntutan peran timbal balik antara guru dan siswa. Berkaitan dengan kualitas bahan ajar berdasarkan hasil penilaian dari validator dan uji coba kelompok kecil dapat disimpulkan bahwa Berdasarkan penilaian dari validator diketahui bahwa secara keseluruhan bahwa bahan ajar ini tergolong dalam kategori sangat baik dengan persentase sebesar 88,33\%. Hal ini menunjukkan bahwa bahan ajar yang dikembangkan layak digunakan sebagai bahan ajar untuk membantu siswa dan guru pada proses pembelajarannya. Berdasarkan uji coba kelompok kecil higher order thinking skill siswa. Setelah menggunakan bahan ajar Kolb-Knisley meningkat dengan persentase ketuntasan sebesar $100 \%$. Beradasarkan uji coba kelompok kecil dapat diketahui bahwa terdapat perbedaan antara apresiasi siswa terhadap matematika baik sebelum dan sesudah pembelajaran dengan menggunakan produk yang dikembangkan. Adapun rata-rata apresiasi siswa terhadap matematika sebelum menggunakan produk yang dikembangkan sebesar 73,66 dan berada pada kategori sedang. Sedangkan apresiasi siswa terhadap matematika setelah menggunakan produk yang dikembangkan sebesar 103,60 dan berada pada kategori sangat tinggi. Berdasarkan hasil angket respon siswa terhadap bahan ajar KolbKnisley diperoleh persentase sebesar 95\%. Sehingga secara keseluruhan, bahan ajar Kolb-Knisley yang telah dikembangkan oleh pengembang diketahui sangat baik. 


\section{DAFTAR PUSTAKA}

Ahmadi, I. K., dkk. (2011). Strategi pembelajaran sekolah terpadu. Jakarta: PT. Prestasi Pustakaraya.

Amalia, R. (2013). Penerapan model pembelajaran pembuktian untuk meningkatkan kemampuan berpikir matematis tingkat tinggi siswa SMA. Skripsi. Universitas Pendidikan Indonesia, Bandung.

An, S., Kulm, G., \& Wu, Z. 2004. The pedagogical content knowledge of middle school. Mathematics teachers in China and the U.S. Journal of Mathematics Teacher Education, 7, 145-172.

Barret, T. 2007. Teaching toward appreciation. Dalam L. Bresler (Eds.), International Handbook of Research of Arts Education (pp. 639-654). New York, NY: Springer.

Departemen Pendidikan Nasional. 2007. Peraturan menteri pendidikan nasional Republik Indonesia No. 41 Tahun 2007 tentang standar proses untuk satuan pendidikan dasar dan menengah. Tersedia pada: http://www.bsnpindonesia.org/standards-proses.php.

Heong, Y. M., Othman, W. D., Yunos, M. J., Kiong, T.T., Hassan, R., \& Mohamad, M. M. (2011). The level of marzano higher order thinking skills among technical education students. International Journal of Social and Humanity, Vol. 1, No. 2, July 2011, 121-125.

Hohenwarter, M ., \& Fuchs, K. (2004). Combination of dynamic geometry, algebra, and calculus in the software system geogebra. Tersedia di http://www.geogebra.org.

Knisley, J. (2003). A Four-Stage Model of Mathematical Learning. Dalam Mathematics Educator [Online], Vol 12 (1) 10 halaman. Tersedia: http//Wilson Coe.uga.edu/DEPT/TME/Issues/ v12n1/ 3knisley. HTML.

Majid, A. (2009). Perencanaan pembelajaran. Bandung: PT. Remaja Rosdakarya.

Wijaya, A. (2012). Pendidikan matematika realistik suatu alternatif pendekatan pembelajaran matematika. Yogyakarta: Graha Ilmu. 